\title{
A rare complication after renal transplantation: Forgotten stent
}

\author{
Mustafa Karabicak, Tumay Ipekci, Cemal Selcuk Isoglu, Mehmet Zeynel Keskin, Rahmi Gokhan Ekin, \\ Salih Budak, Hakan Turk, Orcun Celik, Yusuf Ozlem Ilbey
}

Tepecik Education and Research Hospital, Urology Clinic, Izmir, Turkey.

\begin{abstract}
Summary In renal transplantation surgery, double J stents (DJS) are often used to reduce complications, protect the anastomosis between ureter and bladder, provide drainage in ureteral obstructions and enhance healing if there is an ureter injury.

Urinary tract infections, hematuria and irritative voiding symptoms are the early complications of DJS. Migration, fragmantation, encrustation and rarely sepsis are among the late complications of DJS. In this report we describe a renal transplantation case whose DJS stent was forgotten because the patient did not attend the regular follow-up and noticed 5 years after surgery.
\end{abstract}

KEY WORDS: Double J stent (DJS); Urinary tract infection (UTI); Extracorporal Shockwave Lithotripsy (ESWL);

Ureterorenoscopy (URS); Oercutaneous nephrolithotomy (PNL).

Submitted 5 January 2015; Accepted 15 March 2015

\section{INTRODUCTION}

Double J stent is an useful tool that is commonly used in many urological procedures.

In renal transplantation surgery, double J stents (DJS) are often used to reduce complications, protect the anastomosis between ureter and bladder, provide drainage in ureteral obstructions and enhance healing if there is an ureter injury $(1,2)$.

Complications caused by DJS are seen with a rate of $2.2 \%$ in renal transplant patients (1). Complications like migration, fragmentation and encrustation can cause obstructive nephropathy (3). In this report we described a renal transplantation case whose DJS stent was forgotten becasue of not attending the regular follow-up and noticed 5 years after surgery.

\section{Case report}

A 55 years old male patient presented to the hospital with recurrent urinary tract infection.Patient had a renal transplantation surgery 5 years before due to chronic kidney disease caused by high blood pressure and did not apply for regular follow up. Physical examination was normal except the suprapubic pain. Laboratory tests were in normal ranges but Escherichia coli was detected in urine cul-

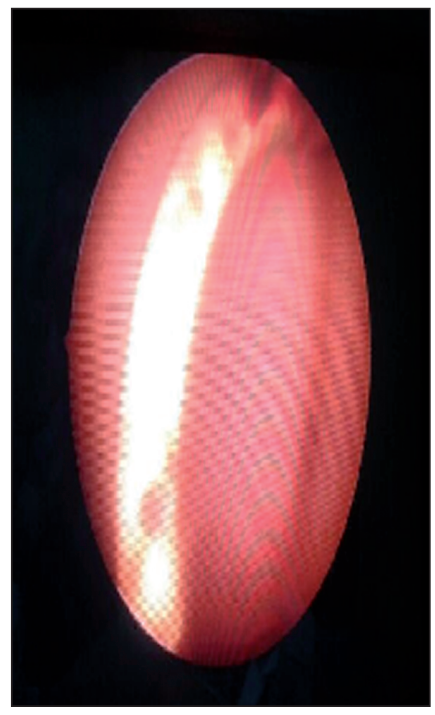

\section{Figure 1.}

Cytoscopic view of

double J stent.

ture. At ultrasonography, patient's native kidneys were athropic and the transplanted kidney was seen in the right lower quadrant. Parenchymal thickness of the transplanted kidney was normal but mild pyelectasis was detected. DJS was seen in the bladder also with X-ray. Patient was informed about the procedure and informed consent was obtained. DJS was removed endoscopically. The patient was discharged after antibiotic treatment without any problem.

Figure 2.

Double $J$ stent removed from the patient

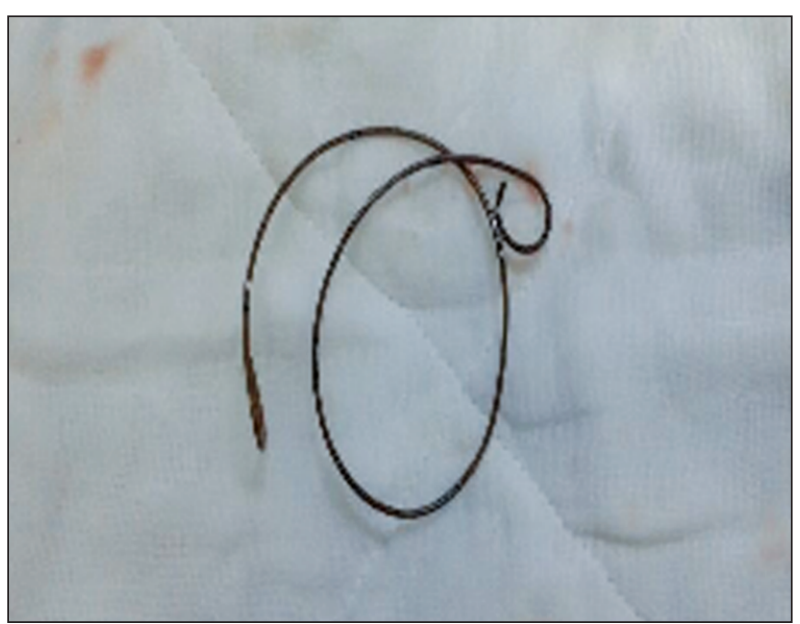




\section{Discussion}

There is no consensus about the removal time of DJS in renal transplanted patients. The removal time varies around 1-12 weeks in different studies (4). However it is prudent to remove the stent in 2-4 weeks after transplantation for preventing the possible complications (5). There is no clear definition for forgotten DJS but in some studies the stent was defined as forgotten when was retained more than 6 months (2).

Complications caused by DJS are observed with a rate of $2.2 \%$ in renal transplant patients (1). Urinary tract infections (UTI), hematuria and irritative voiding symptoms are the early complications of DJS. Migration, fragmentation, encrustation and rarely sepsis are among the late complications of DJS. Our patient was suffering from recurrent UTI and irritative voiding symptoms. A biofilm layer covers long-term retained stents and it can cause UTI by contact with urine. Urine pH can increases due to urea splitting bacterias that decompose urea and cause magnesium-calcium-phosphate cyristals accumulation on the DJS. Encrustation is highly related with urine composition, bacterial colonisation and duration of staying of the stent (6). There is no proofed gold standard treatment for encrusted stents. Extracorporeal shock wave lithotripsy and percutanous nephrolithotomy are recommended for proximal encrustation, ureterorenoscopy is recommended for distal encrustations. Because of the immunosupression, all patients should be assessed for UTI and after removal should be carefully evaluated for sepsis, urinary tract injury and UTI (7). In our case, DJS was seen with cystoscope and removed with foreign body forseps.

In conclusion, forgotten DJS can cause severe urological problems in renal transplanted patients. Multimodal urological approach is necessary for treatment. All patients should be evaluated carefully for UTI and sepsis because of the immunosupression and antibiotics are recommended for prophlaxy. Patients should be informed about the complications of DJS and the importance of regular follow-up (7). In cases of recurrent UTI after renal transplantation, possible retention of DJS should always be kept in mind.

\section{REFERENCES}

1. Nicol DL, P'ng K, Hardie DR, et al. Routine use of indwelling ureteral stents in renal transplantation. J Urol. 1993; 150:1375-9.

2. Aravantinos E, Graves S, Karatzas AD, et al. Forgotten, encrusted ureteral stents: a challenge problem with an endourologic solution. J Endourol. 2006; 20:1045-9.

3. Monga M, Klei E, Castaneda-Zuniga WR, et al. The forgotten indwelling ureteral stent: a urological dilemma. J Urol. 1995; 153:1817-9.

4-Verma BS, Bhandari M, Srivastava A, et al. Optimum duration of J.J. Stenting in live related renal transplantation. Indian J Urol. 2002; 19:54-7.

5. Singh V, Srinivastava A, Kapoor R, Kumar, A. Can the complicated forgotten indwelling ureteric stents be lethal? Int Urol Nephrol. 2005; 37:541-6.

6-Vanderbrink BA, Rastinehad AR, Ost MC, Smith AD. Encrusted urinary stents: Evaluation and endourologic management. J Endourol. 2008; 22:905-12.

7. Shaheel Bhuva, Steven J, Kennish, Tze M Wah. Forgotten indwelling stent in a transplanted kidney. Cases Journal. 2009; 2:27.

\section{Correspondence}

Mustafa Karabicak, MD

bicak_7@hotmail.com

Tumay Ipekci, MD

Cemal Selcuk Isoglu, MD

Mehmet Zeynel Keskin, MD

Rahmi Gokhan Ekin, MD

Salih Budak, MD

Hakan Turk, MD

Orcun Celik, MD

Yusuf Ozlem Ilbey, MD

Tepecik Education and Research Hospital, Urology Clinic

Izmir, Turkey 